\title{
Erratum to: Novel Approaches to Inhibition of Gastric Acid Secretion
}

\author{
George Sachs • Jai Moo Shin • Richard Hunt
}

Published online: 12 November 2010

(C) Springer Science+Business Media, LLC 2010

Erratum to: Curr Gastroenterol Rep

DOI 10.1007/s11894-010-0149-5

The original version of this article unfortunately contained a mistake. The acknowledgement section was missing in the published article. The acknowledgement section is stated as follows.

Acknowledgement This work was supported by US VA Merit Grant, NIH/NIDDK grant number's DK053642 and DK058333.

The online version of the original article can be found at http://dx.doi. org/10.1007/s11894-010-0149-5.

G. Sachs $(\bowtie) \cdot$ J. M. Shin

Department of Physiology and Medicine,

David Geffen School of Medicine,

University of California at Los Angeles,

and VA Greater Los Angeles Healthcare System,

Room 324, Building 113, 11301 Wilshire Boulevard,

Los Angeles, CA 90073, USA

e-mail: gsachs@ucla.edu

J. M. Shin

e-mail: jaishin@ucla.edu

R. Hunt

Farncombe Family Digestive Disease Research Institute,

Division of Gastroenterology,

McMaster University Health Sciences Centre,

1200 Main Street West, Room 4W8A,

Hamilton, ON L8N 3Z5, Canada

e-mail: huntr@mcmaster.ca 